\title{
STUDY OF CRITERIA FOR EVALUATION OF TRANSPORTATION WITH INTERMODAL TRANSPORT
}

\author{
Svetla Stoilova, Lilo Kunchev \\ Technical University - Sofia, Bulgaria \\ stoilova@tu-sofia.bg, kunchev@tu-sofia.bg
}

\begin{abstract}
The present study defines criteria for evaluation of intermodal passenger and freight transportation integrated railway and road transport (motorail trains and Ro-La trains). This type of transportation improves the efficiency of distribution in the supply chain. Two variants of criteria are studied in the paper - main and extended. The main criteria are divided into four groups: environmental, economic, technological and social. Eleven factors have been examined in the extended criteria: environmental, operating costs, transportation fares, infrastructure charges, duration of transportation, transportation from door to door, duration of transshipment operations, comfort, safety, reliability and stability. The method of multi-criteria analysis Decision Making Trial and the Evaluation Laboratory (DEMATEL) method have been applied to analyze the importance and the relations among the criteria. The summarized results of both variants are similar. They show that the economic criteria have the greatest impact. Operating costs are the key factor among the extended variant of criteria. Other criteria of great importance are also duration of transportation and transport from door to door. The defined criteria can be applied for the evaluation, comparison and selection the transportation with different modes of transport.
\end{abstract}

Keywords: DEMATEL method, Multi-criteria analysis, intermodal transport, railway transport, Ro-La, motorail.

\section{Introduction}

Intermodal transportation combines two or more modes of transport to achieve the most economic, efficient and environmentally-friendly transportation of goods and passengers to a destination.

The intermodal passenger transport - motorail trains, which offer convenience for passengers to travel from door to door in their own car and intermodal freight transport - Rolling Highway (Ro-La), when the truck, including the driver, travel by train are applied in many countries in Europe, both for domestic and international transport. The service with motorail trains is organized in France, Germany, Austria, the Czech Republic, Croatia, Finland, and Italy. In Bulgaria from 2002 to 2004 service for private cars by train for two destinations was introduced: Sofia-Karlovo-Varna and SofiaPlovdiv-Burgas. The service has been terminated due to the insufficient number of specialized wagons. The intermodal freight transport Ro-La appeared in the European Union countries to facilitate freight traffic. This technology is experiencing a great development in Austria, Hungary, Switzerland and Slovenia, countries that have introduced a restrictive policy regarding the movement of heavy vehicles on public roads. Studies for introducing this type of transport are also being done in Bulgaria.

The choice of criteria for assessing the type of transportation is an important task for choosing the transport technology. The prioritisation of the criteria would make it possible to evaluate various schemes of transportation with various modes of transport or different forms of intermodal transport.

An important aspect of the choice of criteria of international railway freight transport was examined in [1]. They established six key performance indicators in transport chains: transport cost, transport time, flexibility, reliability, quality, and sustainability. In [2] the quality indicators of intermodal terminals are defined: flexibility, safety and security, reliability, time, and accessibility. Based on these quality indicators location criteria are formed and evaluated: legislative, environmental, goods flows, spatial, technical-technological, and organizational. The quality and performance indicators for intermodal terminals are defined in [3]. The problems of railway passenger and road transport are investigated in [4-7]. In [8] using the AHP method the authors studied the four main criteria related to the efficiency of freight transportation and the transportation system: the cost of cargo delivery, time of delivery, reliability of cargo transportation and ecological impact. Intermodal passenger transportation with motorail trains is studied in [9]. The research defines six groups of main criteria to prioritize the variant routes: frequency, possibility for passengers to sleep during the journey; possibility for passengers to enjoy their free time during the trip; environmental factors; preference of passengers for a day or a night trip and the payback period. 
Multi-criteria analysis methods allow for evaluation of the defined criteria. The most often used multi-criteria method for decision making is the Analytic Hierarchy Process (AHP). The Decision Making Trial and Evaluation Laboratory (DEMATEL) methodology has been used by various researchers to solve problems in different areas and to analyse interrelationships among criteria. The DEMATEL method has been applied in transport to evaluate criteria for maritime transport [10]; for vehicle fleet maintenance management [11]; for tourism marketing [12]; in supply chain management [13]. The DEMATEL approach has been applied in [14], where thirteen criteria are defined in order to study the influential criteria of carbon management in green supply chain.

This paper aims to propose an approach for examining the criteria for intermodal transportation, their impact and relationship by taking into account the transportation process. In this paper we have studied intermodal passenger transport - motorail trains, which offer convenience for passengers to travel from door to door in their own car and intermodal freight transport - Rolling Highway (Ro- La), when the truck, including the driver, travel by train.

\section{Materials and methods}

In the paper two variant groups of criteria have been proposed for the study of intermodal motorail and Ro-La transportation:

\section{Variant 1: Main group of criteria}

- F1: Environmental criteria. These criteria include carbon dioxide and pollutant emissions during transportation. Intermodal transport is environmental friendly. Most railways where intermodal trains run are electrified, thus the carbon dioxide emitted during the production of the electricity should be taken into account.

- F2: Economic criteria. It includes the operational costs, fares, infrastructures charges, ticket price.

- F3: Technological criteria. This criterion contains the time spent travelling in hours, possibility of transportation from door to door, duration of transhipment operations.

- F4: Social criteria. It refers to comfort, safety and reliability.

\section{Variant 2: An expanded group of criteria}

- S1: Environmental criterion. This criterion is the same as F1 criterion in Variant 1.

- S2: Operational costs for intermodal transportation. They include the cost of power consumption, maintenance and repair of rolling stock, personnel, depreciation allowances and other operational expenses.

- S3: Transportation fare. For intermodal passenger transport - motorail trains - the fare includes the ticket for transportation, the fare for loading the car onto the wagon. For intermodal Ro-La transport this fare includes everything provided for in the tariffs of the carrier as basic and additional charges.

- S4: Infrastructure charges. They depend on the distance of transportation and on gross weight. Gross weight depends on the number of wagons in the composition of the train; the capacity of the railway infrastructure.

- S5: The duration of transportation with motorail or Ro-La trains. It depends on the condition of the railway infrastructure and the rolling stock.

- S6: Transport from door to door. For intermodal passenger transport - motorail - this means the possibility for a passenger to travel from their home to the station in their own car, then load the car on the motorail train and in the final station again to travel by car to the final destination. For intermodal Ro-La transport this means to carry cargo from the start to the final point in one loading unit without overloading.

- S7: Duration of transhipment operations. It depends on the technique of overloading.

- S8: Comfort. For motorail trains this is expressed by the possibility for passengers to have a rest while traveling; to use the toilet, the restaurant, and Internet; the possibility for passengers to move around during transportation. In accompanied Ro-La transport truck drivers can relax during the journey in a separate car. In unaccompanied Ro-La transport drivers do not travel with the trucks and can relax until the next shipment. 
- S9: Security. The big distance on the itinerary of the intermodal passenger and cargo transport under study is covered by railway transport which is characterized by a high degree of security because the movement is carried out in an independent infrastructure.

- S10:Reliability. This is means meeting the deadline for the delivery of cargo and accurate schedule of trains.

- S11: Stability. There is lack of dependence between intermodal transportation and season.

This research applies the DEMATEL method to study the criteria and their interdependencies and so convert the relationship between the causes and effects of criteria into a structural model.

The procedure of DEMATEL method is summarized as follows [11]:

Step 1: Create experts' perception matrixes $X^{1}, X^{2}, \ldots, X^{H}$, where $k=1, \ldots, H$ is the number of experts. The number of factors that have to be evaluated is $n$. Each expert evaluates the direct influence between any two factors by an integer score with a following meaning: 0 - no influence; 1 - low influence; 2 - medium influence; 3 - high influence; 4 - very high influence. For each expert $k$, an $n x n$ non-negative matrix can be established as $X^{k}=\left\lfloor x_{i j}^{k}\right\rfloor_{n x n}$, where $n$ is the number of criteria.The notation of $x_{i j}$ indicates the degree to which the expert assesses the factor $I$ affects the factor $j$. For $i=j$, the diagonal elements of each expert answer matrix are set to zero.

Step 2: Calculate the average perception matrix $A=\left\lfloor a_{i j}\right\rfloor_{n x n}$. To include all opinions from the experts, the average answer matrix $A$ could be calculated as follows:

$$
a_{i j}=\frac{1}{H} \sum_{k=1}^{H} x_{i j}^{k}
$$

Step 3: Calculate the average normalized perception matrix $D=\left\lfloor d_{i j}\right\rfloor_{n \times n}$.

$$
D=\frac{A}{S},
$$

where $A$-average answer matrix;

$S$ - major value of the sum of each column $j$ of the matrix $A$ and the major value of the sum of each row $i$ of the matrix $A$.

The value of $S$ is calculated as follows:

$$
S=\max \left(\max (1 \leq i \leq n) \sum_{j=1}^{n} a_{i j} ; \max (1 \leq i \leq n) \sum_{j=1}^{n} a_{i j}\right)
$$

The values of each element in the matrix $D$ are between zero and one.

Step 4: Calculate the total relation matrix $T=\left\lfloor t_{i j}\right\rfloor_{n x n}$.

$$
T=D(I-D)^{-1}
$$

where $I-n x n$ identity matrix.

The sums of rows and columns of the $T$ matrix are represented by a $R$ vector and a $C$ vector

$$
\left.R=\left[r_{i}\right]_{n x 1}=\mid \sum_{j=1}^{n} t_{i j}\right\rfloor_{n x 1}
$$

where $r_{i}$-sum of the $i$-th row in the matrix $T . r_{i}$ shows the total effect, both direct and indirect effects by the $i$-th factor on the other factors.

It summarizes both direct and indirect effects given by the factor $i$ to the other factors

$$
C=\left[c_{i}\right]_{1 x n}^{\prime}=\left[\sum_{j=1}^{n} t_{i j}\right]_{1 x n}
$$

where $c_{j}$ - denotes the sum of $j$-th column in the matrix T. $c_{j}$ shows both direct and indirect effects by the factor $j$ from the other factors.

' - symbol means transposed matrix. 
In the case of $i=j$, term $\left(r_{i}+c_{i}\right)$ indicates a degree of importance of the factor in the system. The sum $\left(r_{i}+c_{i}\right)$ gives an index (the position) representing the total effects both given and received by the $i$-th factor. The term $\left(r_{i}-c_{i}\right)$ represents the net effect that the criterion contributes to the system in relation to other factors. If $\left(r_{i}-c_{i}\right)$ is positive, the factor $i$ is a net cause, if $\left(r_{i}-c_{i}\right)$ is negative, the factor $i$ is a net receiver [15].

The normalized degree of influence of each criterion can be determined as follows:

$$
e_{i}=\frac{r_{i}+c_{i}}{\sum_{i=1}^{n} r_{i}+c_{i}} \cdot 100 \%
$$

Step 5: Set a threshold value $p$ and obtain a cause and effect relationship diagram. This calculation is aimed to eliminate some minor effect elements in matrix $T$. The value of $p$ can be obtained in different ways. In [16] the value $p$ is determined as an average value of the elements of the matrix $T$. In [17] the threshold value is determined by adopting the concepts of fractional factorial design, in [12] this value is defined by using the maximum mean de-entropy algorithm. The threshold value can be set by experts, [17]. In this research the threshold value $p$ is determined as average value as follows:

$$
p=\frac{\sum_{i=1}^{n} \sum_{j=1}^{n}\left[t_{i j}\right]}{N},
$$

where $N$-total number of elements in the matrix $T$.

The threshold value serves to determine the relationships in the considered system. The value of elements of the matrix $T$, which are smaller or equal to the adopted value $p$, is set to zero. The other elements of the matrix $T$ which are larger than the adopted value $p$, retain their present value.

The relationship diagram is constructed by mapping all coordinate sets by $\left(r_{i}+c_{i}\right),\left(r_{i}-c_{i}\right)$ to visualize the complex interrelationship and provide information to determine, which are the most important factors and how they influence the affected factors. The diagram includes the factors that $t_{i j}$ is greater than the threshold value $p$. Based on the coordinate positions of $\left(r_{i}+c_{i}\right)$ and $\left(r_{i}-c_{i}\right)$, the attributes can be divided into the following 4 types: if $\left(r_{i}-c_{i}\right)$ is positive and $\left(r_{i}+c_{i}\right)$ is large, this indicates that the criteria are causes, which are also key factors for solving problems; if $\left(r_{i}-c_{i}\right)$ is positive and $\left(r_{i}+c_{i}\right)$ is small, this indicates that the criteria are independent and can influence only a few other factors; if $\left(r_{i}-c_{i}\right)$ is negative and $\left(r_{i}+c_{i}\right)$ is large, this indicates that the criteria are the core problems that must be solved; however, these are effect-type criteria, which are of indirect impact; if $\left(r_{i}-c_{i}\right)$ is negative and $\left(r_{i}+c_{i}\right)$ is small, this indicates that the factors are independent and can be influenced by only a few other attributes.

\section{Results and discussion}

The evaluation of criteria by 23 experts is used to research the two variants. The experts are specialists with long experience in transport (6), specialistsfrom the railway and automotive administration (4), managers of transport companies (5), researchers with wide knowledge of quality management (5) and truck drivers (3). The study was conducted as each expert fills a table with score of the pair-wise comparisons between the criteria using assessments ( 0 to 4$)$ according to step 1 of the method. This is done separately for variant 1 and variant 2. MS Excel was used to process the results and conduct the study. Table 1 shows the average value of the assessments of the experts for variant 1 using formula (1). Table 2 presents the results of total relation matrix and indirect influence for variant 1. In this table in bold the values equal or greater than the threshold value are indicated. The threshold value determined by formula ( 8 ) for variant 1 is 0.246 . The sum of columns and rows $(R+C)$ called "Prominence" means that all criteria are relatively important. According to the difference $(\mathrm{R}-\mathrm{C})$ named "Relation" the criteria are divided into a cause and effect group depending upon the positive and negative values of all the elements in the $(\mathrm{R}-\mathrm{C})$ column.

The importance of the criteria can be prioritized by the $(\mathrm{R}+\mathrm{C})$ column.Considering the value of their respective $(\mathrm{R}-\mathrm{C})$ score the criteria have been divided into cause group factors and effect group factors. The cause group factors have a direct impact on the overall system. 
Average Matrix of Variant 1

Table 1

\begin{tabular}{|c|c|c|c|c|}
\hline Criteria & F1 & F2 & F3 & F4 \\
\hline F1: Environmental criteria & 0.00 & 0.09 & 0.43 & 0.17 \\
\hline F2:Economic criteria & 1.826 & 0.00 & 2.87 & 2.22 \\
\hline F3:Technological criteria & 0.043 & 1.87 & 0.00 & 0.96 \\
\hline F4:Social criteria & 0.043 & 0.87 & 1.96 & 0.00 \\
\hline
\end{tabular}

Table 2

Total Relation Matrix $\mathbf{T}$ and the direct and indirect influence for Variant 1

\begin{tabular}{|c|c|c|c|c|c|c|c|c|c|}
\hline & $\mathbf{F 1}$ & $\mathbf{F 2}$ & $\mathbf{F 3}$ & $\mathbf{F 4}$ & $\mathbf{R}$ & $\mathbf{C}$ & $\mathbf{R}+\mathbf{C}$ & $\mathbf{R}-\mathbf{C}$ & $\boldsymbol{e}_{\boldsymbol{i}}$ \\
\hline F1 & 0.013 & 0.046 & 0.098 & 0.054 & 0.21 & 0.54 & 0.75 & -0.33 & $9.50 \%$ \\
\hline F2 & $\mathbf{0 . 3 3 8}$ & $\mathbf{0 . 2 5 3}$ & $\mathbf{0 . 6 8 4}$ & $\mathbf{0 . 5 0 5}$ & 1.78 & 0.94 & 2.72 & 0.84 & $34.43 \%$ \\
\hline F3 & 0.109 & $\mathbf{0 . 3 7 6}$ & $\mathbf{0 . 2 4 6}$ & $\mathbf{0 . 2 9 6}$ & 1.03 & 1.47 & 2.49 & -0.44 & $31.59 \%$ \\
\hline F4 & 0.080 & $\mathbf{0 . 2 6 4}$ & $\mathbf{0 . 4 3 9}$ & 0.147 & 0.93 & 1.00 & 1.93 & -0.07 & $24.47 \%$ \\
\hline
\end{tabular}

The results in Table 2 show:

- F2criterion (Economic criteria) has the highest degree of importance.

- The prioritization is $\mathrm{F} 2>\mathrm{F} 3>\mathrm{F} 4>\mathrm{F} 1$.

- F2 and F3 criteria (Economic and Technological criteria) have close values.

- According to the results and Table 2 the F2criterion is in the cause group $((\mathrm{R}-\mathrm{C})$ is positive).

- The criteria in the effect group are F1, F3 and F4 ((R - C) are negative). They are influenced by other factors.

- Of all the effect group factors F3 (Technological criteria)obtain thelowest (R - C) score, i.e. 0.44, which implies that this factor receives the maximum impact from all other factors. This criterion is in the second position of importance according to $(\mathrm{R}+\mathrm{C})$ score.

Fig. 1 presents the cause and effect diagram of Variant 1. The results show:

- It can be seen that for F2 $(\mathrm{R}-\mathrm{C})$ is positive and $(\mathrm{R}+\mathrm{C})$ is large. This indicates that the F2 criterion (Economic criteria)is a key factor for solving problems.

- F1criterion (Environmental criteria)has negative $(\mathrm{R}-\mathrm{C}$ )and small $(\mathrm{R}+\mathrm{C})$, which shows that it is independent and can be influenced by a few other factors.

- $\mathrm{F} 3$ and F4 criteria (Economic and Technological criteria)have negative (R - C)and large (R + C). This shows that they have indirect impact on the studied system.

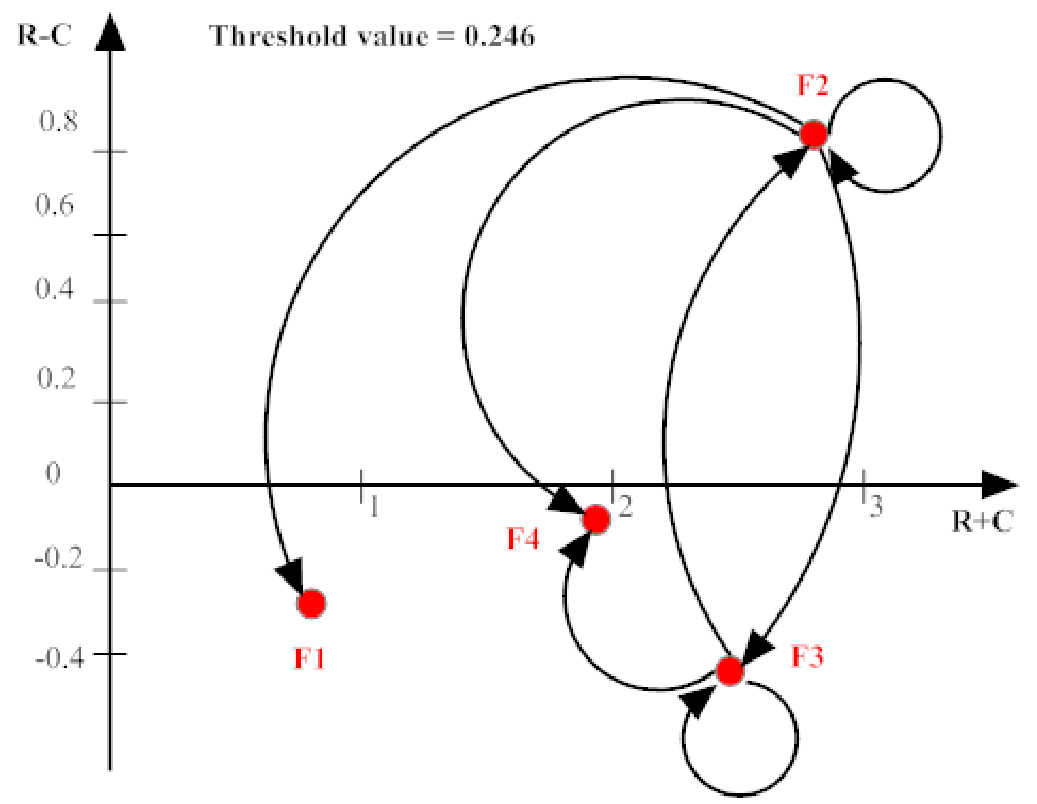

Fig. 1. Cause and effect diagram of Variant 1 
Table 3 shows the average value of the assessments of experts for variant 2. Table 4 presents the Total Relation Matrix for this variant. The threshold value is 0.0754 . In Table 4 in bold the values equal or greater than the threshold value are indicated. Table 5 shows the direct and indirect influence for Variant 2.

Table 3

Average Matrix of Variant 2

\begin{tabular}{|l|c|l|c|c|c|c|c|c|c|c|c|}
\hline & S1 & S2 & S3 & S4 & S5 & S6 & S7 & S8 & S9 & S10 & S11 \\
\hline S1 & 0 & 2.783 & 0 & 0 & 0.086 & 0.739 & 0 & 0.608 & 0.826 & 0 & 0 \\
\hline S2 & 3.956 & 0 & 0.869 & 0.783 & 3.782 & 3.869 & 0 & 1.956 & 1.956 & 0.043 & 0.43 \\
\hline S3 & 0.43 & 0.043 & 0 & 0 & 2.304 & 0.913 & 2.956 & 3.043 & 0.043 & 0.43 & 0 \\
\hline S4 & 0 & 0.043 & 2.304 & 0 & 3.913 & 1.043 & 0 & 0 & 1.043 & 0 & 0 \\
\hline S5 & 0.608 & 1.956 & 1.043 & 0 & 0 & 0.869 & 0.043 & 0.043 & 0.43 & 1.478 & 0.434 \\
\hline S6 & 0.956 & 2.043 & 0.956 & 1.086 & 1.869 & 0 & 0 & 0.956 & 0.43 & 0.434 & 0.043 \\
\hline S7 & 0 & 1.478 & 0.739 & 0 & 2.043 & 1.043 & 0 & 0.043 & 0 & 0.434 & 0 \\
\hline S8 & 0.043 & 3.043 & 0.043 & 0 & 0 & 0 & 0.739 & 0 & 0.043 & 0 & 0 \\
\hline S9 & 0 & 1.869 & 0.13 & 0.043 & 0.739 & 0.782 & 0.608 & 0.43 & 0 & 0.434 & 0.43 \\
\hline S10 & 0.043 & 1.304 & 0.043 & 0.043 & 0.869 & 0.739 & 0.739 & 0.43 & 0.043 & 0 & 0.26 \\
\hline S11 & 0.26 & 0.986 & 0.608 & 0.826 & 0 & 0 & 0 & 1.043 & 1.13 & 0.26 & 0 \\
\hline
\end{tabular}

Total Relation Matrix T for Variant 2

\begin{tabular}{|l|l|l|l|l|l|l|l|l|l|l|l|}
\hline & S1 & S2 & S3 & S4 & S5 & S6 & S7 & S8 & S9 & S10 & S11 \\
\hline S1 & 0.056 & $\mathbf{0 . 2 0 9}$ & 0.024 & 0.016 & 0.072 & $\mathbf{0 . 1 0 0}$ & 0.010 & 0.072 & $\mathbf{0 . 0 7 9}$ & 0.012 & 0.009 \\
\hline S2 & $\mathbf{0 . 2 9 6}$ & $\mathbf{0 . 1 7 8}$ & $\mathbf{0 . 1 0 9}$ & 0.074 & $\mathbf{0 . 3 3 0}$ & $\mathbf{0 . 3 0 8}$ & 0.034 & $\mathbf{0 . 1 8 5}$ & $\mathbf{0 . 1 6 8}$ & 0.046 & 0.042 \\
\hline S3 & 0.061 & $\mathbf{0 . 1 0 3}$ & 0.033 & 0.012 & $\mathbf{0 . 1 9 6}$ & $\mathbf{0 . 1 0 3}$ & $\mathbf{0 . 1 8 5}$ & $\mathbf{0 . 2 0 0}$ & 0.026 & 0.050 & 0.009 \\
\hline S4 & 0.037 & 0.075 & $\mathbf{0 . 1 6 1}$ & 0.011 & $\mathbf{0 . 2 8 2}$ & $\mathbf{0 . 1 0 7}$ & 0.034 & 0.047 & $\mathbf{0 . 0 8 1}$ & 0.033 & 0.011 \\
\hline S5 & $\mathbf{0 . 0 8 4}$ & $\mathbf{0 . 1 7 0}$ & $\mathbf{0 . 0 8 3}$ & 0.016 & 0.073 & $\mathbf{0 . 1 0 7}$ & 0.025 & 0.050 & 0.055 & $\mathbf{0 . 0 9 7}$ & 0.034 \\
\hline S6 & $\mathbf{0 . 1 1 1}$ & $\mathbf{0 . 1 9 4}$ & $\mathbf{0 . 0 9 1}$ & $\mathbf{0 . 0 7 6}$ & $\mathbf{0 . 1 9 2}$ & 0.072 & 0.024 & $\mathbf{0 . 1 0 3}$ & 0.064 & 0.048 & 0.014 \\
\hline S7 & 0.045 & $\mathbf{0 . 1 3 8}$ & 0.068 & 0.013 & $\mathbf{0 . 1 7 4}$ & $\mathbf{0 . 1 0 8}$ & 0.016 & 0.040 & 0.026 & 0.045 & 0.009 \\
\hline S8 & 0.056 & $\mathbf{0 . 2 1 0}$ & 0.024 & 0.013 & 0.065 & 0.058 & 0.049 & 0.034 & 0.033 & 0.010 & 0.008 \\
\hline S9 & 0.045 & $\mathbf{0 . 1 5 7}$ & 0.032 & 0.017 & $\mathbf{0 . 1 0 2}$ & $\mathbf{0 . 0 9 4}$ & 0.045 & 0.058 & 0.028 & 0.039 & 0.032 \\
\hline S10 & 0.037 & $\mathbf{0 . 1 1 7}$ & 0.023 & 0.014 & $\mathbf{0 . 0 9 7}$ & $\mathbf{0 . 0 8 0}$ & 0.049 & 0.050 & 0.024 & 0.013 & 0.021 \\
\hline S11 & 0.043 & $\mathbf{0 . 1 0 0}$ & 0.053 & 0.054 & 0.051 & 0.038 & 0.017 & $\mathbf{0 . 0 8 6}$ & $\mathbf{0 . 0 8 3}$ & 0.024 & 0.006 \\
\hline
\end{tabular}

Direct and indirect influence for Variant 2

\begin{tabular}{|c|c|c|c|c|c|}
\hline & $\mathbf{R}$ & $\mathbf{C}$ & $\mathbf{R}+\mathbf{C}$ & $\mathbf{R}-\mathbf{C}$ & $\mathbf{e}_{\mathbf{i}}$ \\
\hline S1 & 0.660 & 0.870 & 1.530 & -0.210 & $8.47 \%$ \\
\hline S2 & 1.771 & 1.651 & 3.422 & 0.120 & $18.93 \%$ \\
\hline S3 & 0.976 & 0.700 & 1.676 & 0.277 & $9.27 \%$ \\
\hline S4 & 0.878 & 0.315 & 1.193 & 0.562 & $6.60 \%$ \\
\hline S5 & 0.793 & 1.633 & 2.427 & -0.840 & $13.42 \%$ \\
\hline S6 & 0.989 & 1.176 & 2.166 & -0.187 & $11.98 \%$ \\
\hline S7 & 0.681 & 0.489 & 1.170 & 0.193 & $6.47 \%$ \\
\hline S8 & 0.561 & 0.925 & 1.486 & -0.364 & $8.22 \%$ \\
\hline S9 & 0.647 & 0.665 & 1.313 & -0.018 & $7.26 \%$ \\
\hline S10 & 0.525 & 0.417 & 0.942 & 0.108 & $5.21 \%$ \\
\hline S11 & 0.556 & 0.196 & 0.752 & 0.359 & $4.16 \%$ \\
\hline
\end{tabular}


The results show:

- S2criterion (Operational costs) has the highest degree of importance.

- The prioritization is $\mathrm{S} 2>\mathrm{S} 5>\mathrm{S} 6>\mathrm{S} 3>\mathrm{S} 1>\mathrm{S} 8>\mathrm{S} 9>\mathrm{S} 4>\mathrm{S} 7>\mathrm{S} 10>\mathrm{S} 11$.

- S1, S5 and S6 criteria (Environmental criterion, Duration of transportation, Transport from door to door) have an importance close to that of S2 criterion.

- S2, S3, S4, S7, S10 and S11criteria (Operational costs, Transportation fare, Infrastructure charges, Duration of transshipment operations, Reliability, Stability)arein the cause group.

- Factors in the effect group are S1, S5, S6, S8, and S9criteria(Environmental criterion, Duration of transportation, Transport from door to door, Comfort and Security), and are influenced by other factors.

- $\quad$ Of all the effect group factors S1 obtains the lowest $(\mathrm{R}-\mathrm{C})$ score i.e. -0.21, which implies that this factor receives the maximum impact from all other factors. This criterion is in the fifth position by importance according to $(\mathrm{R}+\mathrm{C})$ score.

Figure 2 presents the cause and effect diagram of Variant 2. The results show:

- It can be seen that for $\mathrm{S} 2(\mathrm{R}-\mathrm{C})$ is positive and $(\mathrm{R}+\mathrm{C})$ is large. This indicates that the $\mathrm{S} 2$ criterion is a key factor for solving problems.

- $\quad$ S5 and S8 criteria have negative $(\mathrm{R}-\mathrm{C})$ and large $(\mathrm{R}+\mathrm{C})$. This shows that they have indirect impact on the studied system.

- S3, S4, S7, S10 and S11 criteria have positive $(\mathrm{R}-\mathrm{C})$ and small $(\mathrm{R}+\mathrm{C})$ which indicates that these criteria are independent and influenced only by a few other factors.

- $\quad$ S1, S6 and S9 criteria have negative $(\mathrm{R}-\mathrm{C})$ and small $(\mathrm{R}+\mathrm{C})$, which shows that they are independent and can be influenced by a few other factors.

Fig. 3 presents the percentage value of the criteria and comparesthe results for the two variants. When comparing the variants the criteria of the expanded group are combined. The S2, S3 and $\mathrm{S} 4$ criteria are combined and their total impact is compared with the criterion F2 of variant 1 . The S5, S6 and S7 criteria are combined and compared with F3 of variant 1. The S8, S9, S10 and S11 criteria are combined and compared with the F4 criterion of variant 1.

The results given in Fig. 3 show that:

- The results from bothvariants are similar. This shows that the estimates of experts are correct.

- The economic criteria have the key impact for intermodal transportation.

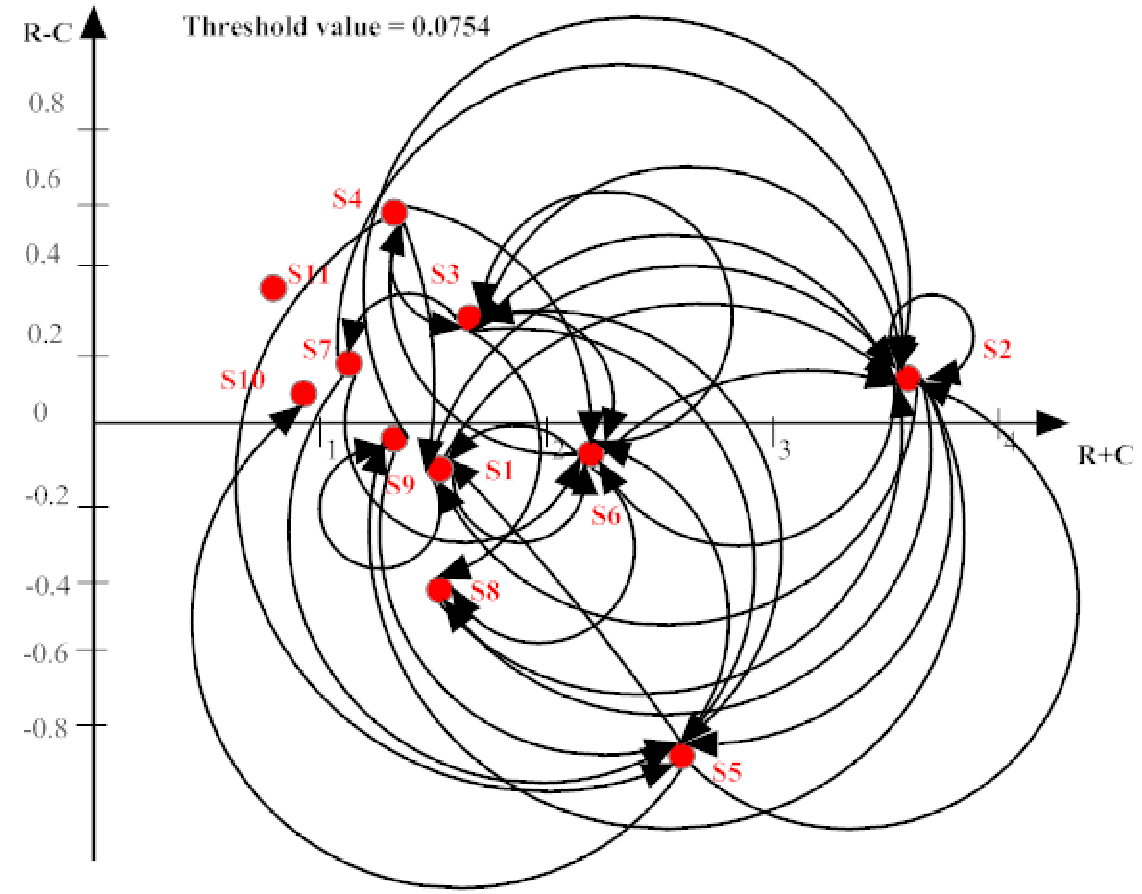

Fig. 2. Cause and effect diagram of Variant 2 


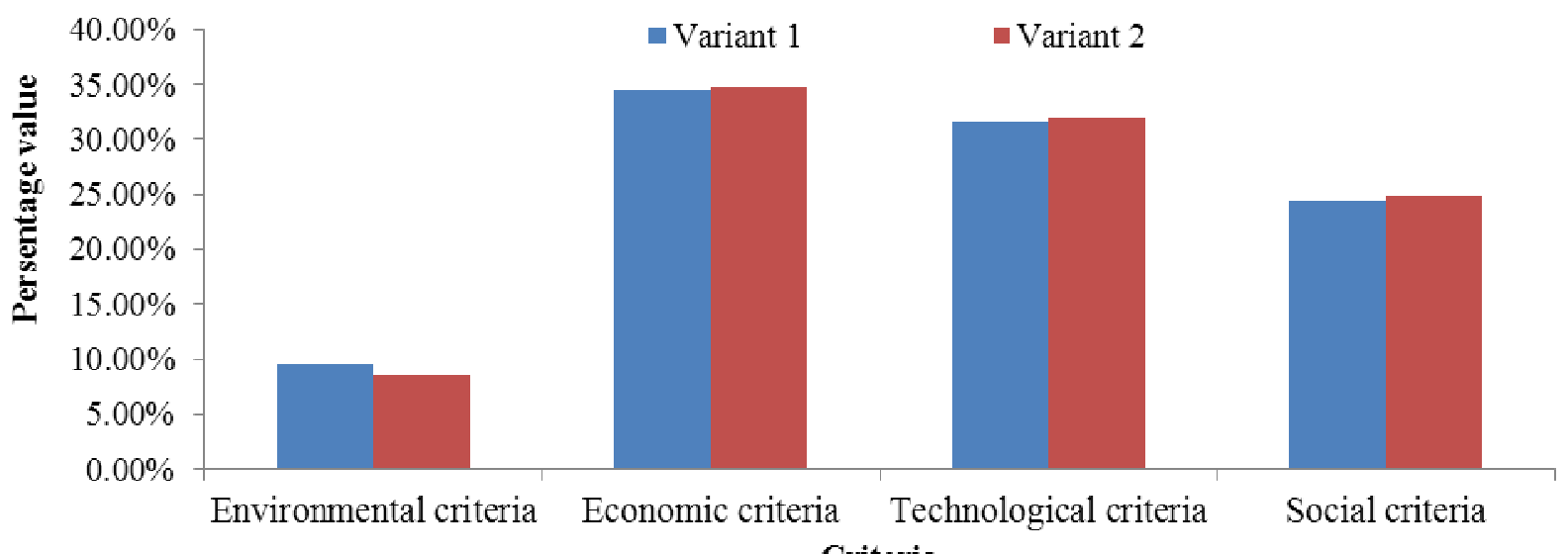

Fig. 3. Comparison of variants

\section{Conclusions}

1. The study definestwo variants of criteria (main and extended)for examining intermodal transportation (motorail trains and Ro-La trains).

2. The DEMATEL method has been applied to study the impact and the influence of the criteria on one another.

3. The causal relations among the criteria for both variants are determined. The environmental, technological and social criteriaare influenced by other factors.

4. The economic criteria are the key factor among the main criteria and they are most important in the investigated system $(34.43 \%)$. The impact of other main criteria are: technological criteria $(31.59 \%)$, social criteria $(24.47 \%)$ and environmental criteria $(9.5 \%)$.

5. Operating costs are the key factor among the extended variant of criteria $(18.93 \%)$. Other criteria of great importance are also duration of transportation (13.42\%) and transport from door to door $(11.98 \%)$.

6. The main criteria give summarized information and could be used for preliminary studies of transportation.

7. The extended criteria give detailed information and could be used when selecting the transport technology.

8. The obtained results can be applied for further research about comparison and choice of the mode of transportation between two points with the participation of intermodal transport.

\section{References}

1. Islam D.M. Z., Zunder T., Jorna R. Performance evaluation ofan online benchmarking tool for European freight transport chains.Benchmarking: An International Journal, Vol. 20, Issue:2, 2013, pp. 233-250.

2. Abramović B., Zitricky V., Biškup V. Organisation of railway freight transport: case study CIM/SMGS between Slovakia and Ukraine, European Transport Research Review, Vol.8(4), 2016, pp. 27.

3. Abramović B., Lovrić I., Supalo V. Analysis of intermodal terminals service quality in the republic of Croatia, Promet - Traffic\&Transportation, Vol. 24, No. 3, 2012, pp. 253-260.

4. Skrucany T., Ponicky J., Kendra M.,Gnap J. Comparison of railway and road passenger transport in energy consumption and ghg production, Proceedings of the "Third international conference on traffic and transport engineering (ICTTE)”, Belgrade,24-25 November, 2016, pp. 744-749.

5. Camaj J., Masek J.,Kendra M. Possibility of applying the common queue of waiting for servicing railway passengers. Proceedings of the "19th Scientific Conference on Transport Means", January, 2015, pp. 147-151.

6. Stoilova S., Kunchev L. Methodology for optimal transportation using a three-phase model.Proceedings of the Bulgarian Academy of Sciences, Vol. 69, Issue No7, 2016, pp. 903-908. 
7. Stoilova S., Kunchev L. Application of the graph theory, AHP method and Cost Benefits Analysis for route selection of a road train. J Balk Tribol Assoc, Vol.22(2), 2016, pp.1041- 1056.

8. Kopytov E., Abramov D. Multiple-criteria choice of transportation alternatives in freight transport system for different types of cargo.Proceedings of the "International Conference Reliability and Statistics in Transportation and Communication",2013,pp. 180-187.

9. Stoilova S. Study of the efficiency of motorail trains as a factor in transport development. Proceedings of the "3rd International Conference on Social Sciences \&Arts-SGEM" 2431August, 2016, Albena, Bulgaria, Book 2, Vol. 5, pp. 627-634.

10. Sener Z. Evaluating Ship Selection Criteria for Maritime Transportation, Journal of Advanced Management Science, Vol. 4, No. 4, 2016, pp. 335-328.

11. Vujanovic D., MomcilovicV., Bojovic N., Papic V.Evaluation of vehicle fleet maintenance management indicators by application of DEMATEL and ANP. Expert Systems with Applications, Vol. 39, 2012, pp.10552-10563.

12. Chen C. Developing Taiwan into the tourist transport centre of East Asia. Tourism Economics, Vol.18 (6), 2012, pp.1401-1411.

13. Gandhia S., Mangla S.K., Kumar P., Kumar D. Evaluating factors in implementation of successful green supply chain. International strategic management review, Vol. 3, 2015, pp. 96-109.

14. Hsua C.-W., Kuo T.-C., Chen S.-H., Hu A.H. Using DEMATEL to develop a carbon management model of supplier selection in green supply chain management. Journal of Cleaner Production, Vol. 56, 2013, pp. 164-172.

15. Yang J. L.,Tzeng G. H. An integrated MCDM technique combined with DEMATEL for a novel cluster-weighted with ANP method, Expert Systems with Applications, Vol. 38, 2011, pp. 1417-1424.

16. Khanam S., Siddiqui J, Talib F. A DEMATEL Approach for Prioritizing the TQM Enablers and IT Resources in the Indian ICT Industry, International Journal of Applied Management Sciences and Engineering, Vol. 3, Issue 1, 2016.

17. Hsieh Y.-F., Lee Y.-C., Lin S.-B. Rebuilding DEMATEL threshold value: an example of a food and beverage information, Springer Plus, Vol. 5(1): 1385, 2016, pp.1-13. 